\title{
Acetylcholinesterase inhibitors and antioxidants mining from marine fungi: bioassays, bioactivity coupled LC-MS/MS analyses and molecular networking
}

\author{
Yingying $\mathrm{Nie}^{1,2} \cdot$ Wencong Yang ${ }^{2} \cdot$ Yayue $\mathrm{Liu}^{2} \cdot$ Jingming Yang ${ }^{2} \cdot$ Xiaoling Lei $^{2} \cdot$ William H. Gerwick ${ }^{3} \cdot$ Yi Zhang $^{1,2,3,4}$
}

Received: 20 April 2020 / Accepted: 19 June 2020 / Published online: 4 September 2020

(c) The Author(s) 2020

\begin{abstract}
Marine fungi are potentially important resources for bioactive lead compounds for discovering new drugs for diseases such as Alzheimer's disease. In this paper, the combined bioassay model of acetylcholinesterase (AChE) inhibition, 1,1-diphenyl2-picrylhydrazyl (DPPH) free radical scavenging, and Artemia larval lethality was used to evaluate the activity and toxicity of 35 marine fungal strains from seas around China. Their bioactive constituents were revealed by thin layer chromatography (TLC) autography, bioactivity coupled LC-MS/MS and Global Natural Products Social Molecular Networking (GNPS). The results show that the extracts of five strains exhibited higher AChE inhibition ratios than the positive control compound, 'tacrine', for which the ratio was $89.8 \%$ at $200 \mu \mathrm{g} / \mathrm{ml}$. Six strains displayed both AChE inhibition (inhibition ratios $>20 \%$ at $200 \mu \mathrm{g} / \mathrm{ml}$ ) and DPPH scavenging activity (scavenging ratios $>30 \%$ at $200 \mu \mathrm{g} / \mathrm{ml}$ ) together with low Artemia larval toxicity (lethal rates $<12 \%$ ). TLC autography showed that the fractioned extracts of four strains contained highly diverse and different bioactive constituents, including strains Talaromyces sp. C21-1, Aspergillus terreus C23-3, Trichoderma harzianum DLEN2008005, and Penicillium corylophilum TBG1-17. From the most potent sample F-11-1-b (derived from Aspergillus

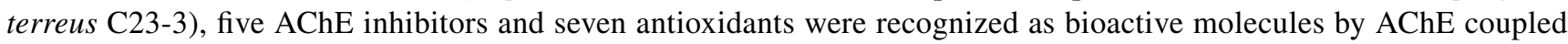
ultrafiltration followed by LC-MS/MS, and LC-MS/MS coupled with DPPH incubation. Furthermore, with the aid of GNPS, the AChE inhibitors were plausibly annotated as territrem analogues including territrems $A-C / D$, arisugacin A and an unknown compound $\mathbf{4}$, and the seven antioxidants were assigned as butyrolactone $\mathrm{I}$, aspernolide $\mathrm{E}$, a phenolic derivative and possibly unknown compounds $\mathbf{8}-\mathbf{- 1 0}$ and $\mathbf{1 2}$.
\end{abstract}

Keywords Acetylcholinesterase inhibition $\cdot$ Antioxidant $\cdot$ Marine fungi $\cdot$ LC-MS/MS $\cdot$ Molecular networking

\section{Introduction}

Alzheimer's disease (AD) is the major form of senile dementia, which seriously threatens the physical and mental health of the elderly. Its main pathological manifestations include the formation of $\mathrm{A} \beta$ plaques and neurofibrillary tangles, the amyloidosis of capillaries and the abnormal damage of

Edited by Chengchao Chen.

Electronic supplementary material The online version of this article (https://doi.org/10.1007/s42995-020-00065-9) contains supplementary material, which is available to authorized users.

Yi Zhang

hubeizhangyi@163.com

Extended author information available on the last page of the article synapses (Goedert 1993; Haass and Selkoe 1993; Scheff et al. 1990; Verbeek et al. 1994; Wilcock and Esiri 1982). Although its exact pathological mechanism still remains undefined, the deficiency of the neurotransmitter acetylcholine (ACh) in the brain and the neuroinflammation and neuronal apoptosis induced by oxidative stress are well accepted among the main factors of AD (Crawley 1993; Kok et al. 2006; Rogers et al. 1996). Thus, inhibitors of acetylcholinesterase (AChE), the enzyme responsible for the hydrolysis of ACh, as well as antioxidant agents including those from nature, are highly valued in the treatment of $\mathrm{AD}$ (Butterfield et al. 2008; Mcgleenon et al. 1999; Mehta et al. 2012; Ye and Wang 2012).

Due to their high biological and chemical diversity, marine fungi are an important resource for many bioactive compounds including potent $\mathrm{AChE}$ inhibitors and antioxidants (Ji and Wang 2016; Jin et al. 2016; Liu et al. 
2019; Nong et al. 2014). However, isolating bioactive compounds from complicated microbial fermentation extracts is a time-consuming and challenging process via traditional methodology, and many known compounds are repeatedly isolated and characterized leading to a waste of resources. To improve natural products research efficiency, there is an urgent need to quickly localize bioactive molecules in crude extracts and perform structural dereplications before the time-consuming process of traditional isolation and structure elucidation.

Bioactivity-coupled liquid chromatography-(tandem) mass spectrometry (Bio-LC-MS/MS) technologies are based on the interaction between small molecules (ligands) and target molecules like receptors, enzymes or free radicals, in a high-throughput manner (Boer et al. 2007; Chen et al. 2010). For macromolecular targets like receptors and enzymes, ultrafiltration liquid chromatography-mass spectrometry (UF-LC-MS) is a suitable analytical method and utilizes the principle that the ligand-target complex can be captured on an ultrafiltration membrane and then subsequently dissociated by organic solvents (Zhao et al. 2016). For small molecular targets like free radicals and metal ions, simple co-incubation followed by LC-MS analysis is able to recognize interacting ligands via a reduction in peak height (Chen et al. 2010).

However, it is difficult to adequately describe new chemical entities by Bio-LC-MS/MS, especially when only low-resolution MS data is obtained. In recent years, the emergence of molecular networking technologies such as Global Natural Products Social Molecular Networking (GNPS; website: https://gnps.ucsd.edu/) has provided a new perspective for the analysis of natural products at early stages of investigation (Allard et al. 2016; Wang et al. 2016). GNPS allows visualization of all of the molecular ions detected in an LC-MS/MS experiment and reveals the chemical relationships among them based on MS/MS similarity. With the accumulated MS data of natural products from global contributors, GNPS has become an important tool for the rapid and large-scale annotation of known compounds, as well as the discovery of novel compounds (Wang et al. 2016). Therefore, the combined use of Bio-LC-MS/MS in companion with GNPS provides a highly efficient pipeline for recognizing bioactive compounds in crude extracts and can provide the annotation of known compounds as well as the indication of structural relatives for novel ones.

In this study, the combined bioassays comprised of AChE inhibition-DPPH free radical scavenging-Artemia larval lethality was used to evaluate the anti-AD related activity and toxicity of 35 marine fungi. The most promising samples were probed for their bioactive molecules via integrated Bio-LC-MS/MS and GNPS analyses. To the best of our knowledge, this is the first report on the application of Bio-LC-MS/MS coupled with GNPS to screen for lead compounds with anti-AD potential from marine fungi.

\section{Results}

\section{Screening for AChE inhibition and DPPH free radical scavenging activities}

Potato sucrose peptone medium (PSP) and malt extract medium (M) were used as a culture medium for 35 marine fungi and 280 fractioned samples were prepared from the 70 fermentation crude extracts by column chromatography on silica gel eluted sequentially with $n$-hexane, dichloromethane, ethyl acetate, and methanol. All samples were applied onto grids on TLC plates and sprayed with AChE enzyme reaction-coloring solution or DPPH solution to preliminarily demonstrate their activity by the appearance of clear zones on a colored background. The results (see details in Supplementary Table S1, Fig. S1) showed that 60 samples had AChE inhibitory activity (from 24 marine fungi) and 47 samples had DPPH radical scavenging activity (from 21 marine fungi). The samples with AChE inhibitory activity were mainly from the fractions eluted by n-hexane, dichloromethane and ethyl acetate, while the samples with DPPH scavenging activity were mainly from the eluents using dichloromethane, ethyl acetate and methanol.

The above active samples were further quantitatively determined for their potency (Fig. 1; Table 1). At the final concentration of $200 \mu \mathrm{g} / \mathrm{ml}$, seven samples (from five strains) exhibited higher AChE inhibition activity than the positive control (Tacrine: inhibition rate of $89.8 \%$ at $200 \mu \mathrm{g} /$ $\mathrm{ml}$ ), and 12 samples (from nine strains) displayed DPPH radical scavenging rate $>50 \%$ (positive control vitamin $\mathrm{C}$ (Vc): $91.6 \%$ at $200 \mu \mathrm{g} / \mathrm{ml}$ ). Moreover, eight extracts of six strains had both AChE inhibitory and antioxidant activities.

\section{Toxicity evaluation of marine fungal extracts}

To identify the bioactive samples with low toxicity, 26 potent samples were evaluated using the Artemia larval lethality assay. The results (Table 1) indicated that the lethal rates of strain $\mathrm{C} 23-3, \mathrm{C} 3-18$ and $\mathrm{C} 23-18$ were $<15 \%$ (the samples with AChE inhibitory activity both antioxidant activity). Among the 14 samples with AChE inhibition rates $>50 \%$, nine samples had lethal rates $<10 \%$ (with AChE inhibition activity only). The seven samples with DPPH radical scavenging rates $>50 \%$ displayed lethal rates $<11 \%$ (only with antioxidant activity). 


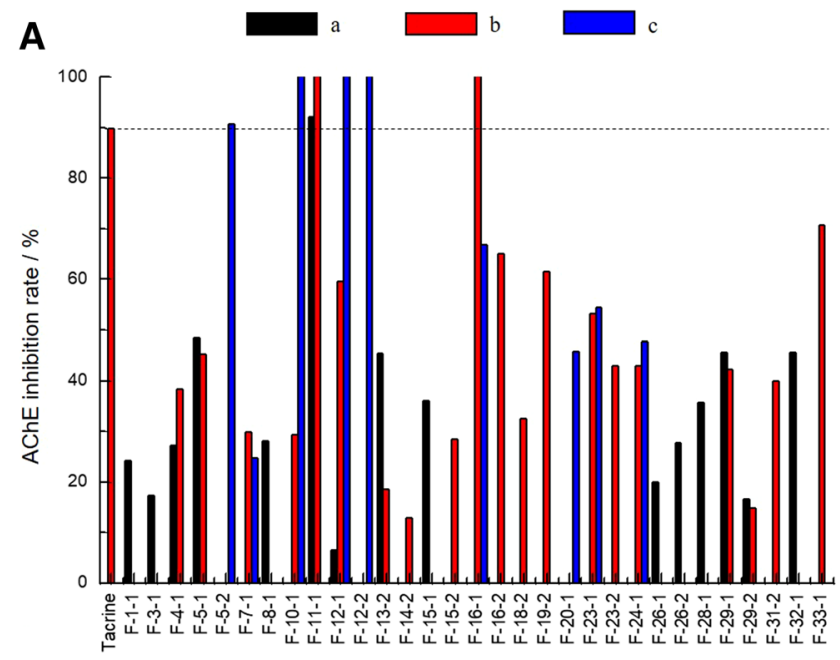

Fig. 1 The AChE inhibitory (A) and antioxidant activity (B) of marine fungal fractioned extracts prepared by different solvent elutions from silica gel columns. The horizontal coordinate numbering principle in the figure: Fungus (F)-strain sequence number-cultural medium. The strain sequence numbers correspond to Table 4 in "Materials and Methods". Medium 1 and 2, respectively, represent

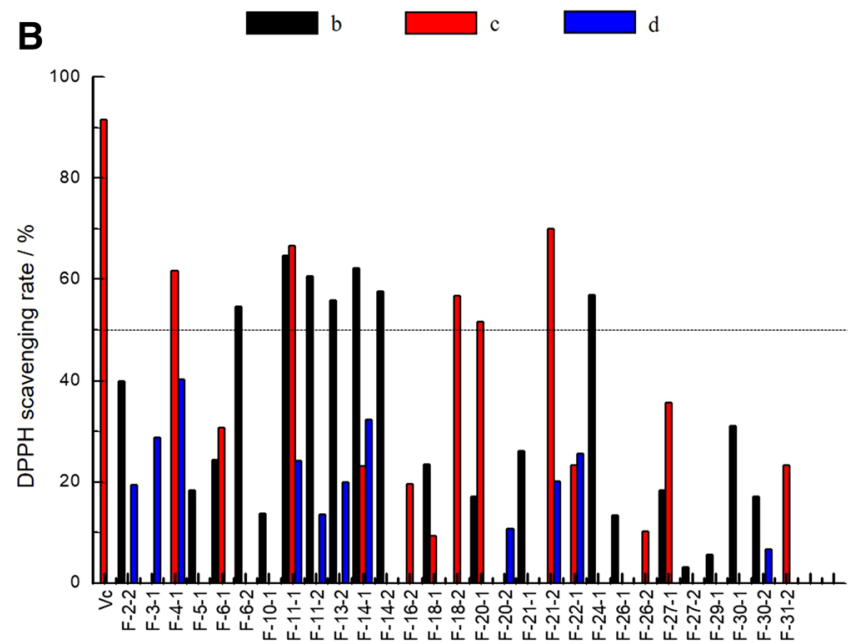

potato medium and malt extract medium. a, b, c and d in the legends refer to the fractionated samples eluted by different solvents: (a) hexane, (b) dichloromethane, (c) ethyl acetate, and (d) methanol, respectively. This numbering scheme also applies to the other parts of this paper

Table 1 Toxicity of marine fungal extracts to Artemia larvae

\begin{tabular}{|c|c|c|c|c|c|c|c|c|c|}
\hline Strains number & $\begin{array}{l}\text { Samples } \\
\text { number }^{\mathrm{a}}\end{array}$ & $\begin{array}{l}\mathrm{AChE} \\
\text { inhibition } \\
\text { rate }(\%)\end{array}$ & $\begin{array}{l}\text { DPPH } \\
\text { scavenging } \\
\text { rate }(\%)\end{array}$ & $\begin{array}{l}\text { Lethal rate } \\
(\%)\end{array}$ & Strains number & $\begin{array}{l}\text { Samples } \\
\text { number }^{\mathrm{a}}\end{array}$ & $\begin{array}{l}\mathrm{AChE} \\
\text { inhibition } \\
\text { rate }(\%)\end{array}$ & $\begin{array}{l}\text { DPPH } \\
\text { scavenging } \\
\text { rate }(\%)\end{array}$ & $\begin{array}{l}\text { Lethal rate } \\
(\%)\end{array}$ \\
\hline ВCT2-3 & F-4-1-c & - & 61.6 & 10.9 & DLEN2008005 & F-16-1-c & 66.7 & - & 0.0 \\
\hline BM3T2 & F-5-1-b & 15.1 & 18.2 & 33.1 & DLEN2008005 & F-16-2-b & 65.0 & - & 7.1 \\
\hline ВM3T2 & F-5-2-c & 90.6 & - & 56.7 & DLEN2008010 & F-18-2-c & - & 56.6 & 0.0 \\
\hline $\mathrm{C} 21-1$ & F-7-1-c & 24.8 & - & 0.0 & DLEN2008016 & F-19-2-b & 61.5 & - & 65.5 \\
\hline C3-1 & F-10-1-c & 100.0 & - & 8.9 & TBG1-6 & F-20-1-c & 45.8 & 51.6 & 63.8 \\
\hline $\mathrm{C} 23-3$ & F-11-1-b & 92.0 & 64.6 & 7.6 & TBG1-12 & F-21-2-c & - & 70.0 & 0.0 \\
\hline $\mathrm{C} 23-3$ & F-11-1-c & 100.0 & 66.6 & 10.9 & TBG1-14 & F-23-1-b & 53.1 & - & 3.5 \\
\hline $\mathrm{C} 23-3$ & F-11-2-b & 34.3 & 60.6 & 0.0 & TBG1-14 & F-23-1-c & 54.4 & - & 0.0 \\
\hline C3-6 & F-12-1-c & 59.6 & - & 0.0 & TBG1-17 & F-24-1-b & - & 57.0 & 0.0 \\
\hline C3-6 & F-12-1-c & 100.0 & - & 0.0 & TBG3-17 & F-29-1-b & 42.2 & 5.6 & 68.5 \\
\hline C3-6 & F-12-2-c & 100.0 & - & 0.0 & $\mathrm{C} 22-2$ & F-33-1-b & 70.7 & - & 25.4 \\
\hline C3-18 & F-13-2-b & 18.5 & 55.9 & 7.0 & positive control & Tacrine & 89.8 & - & - \\
\hline C23-18 & F-14-1-b & - & 62.3 & 10.0 & positive control & $\mathrm{Vc}$ & - & 91.6 & - \\
\hline C23-18 & F-14-2-b & 12.8 & 57.6 & 11.8 & positive control & $\mathrm{CuSO}_{4}$ & - & - & 5.0 \\
\hline DLEN2008005 & F-16-1-b & 100.0 & - & 10.8 & & & & & \\
\hline
\end{tabular}

${ }^{a}$ The sample numbering principle in this table: Fungus (F)-strain sequence number-cultural medium. The strain sequence numbers correspond to Table 4 in "Materials and Methods". Medium 1 and 2, respectively, represent potato medium and malt extract medium

And the $\mathrm{a}, \mathrm{b}, \mathrm{c}$ and $\mathrm{d}$ in the sample numbers refer to the fractional samples eluted by different solvents hexane, dichloromethane, ethyl acetate, and methanol, respectively. This numbering rule also applies to the other sections of this paper

\section{TLC autograph for AChE inhibitory and DPPH radical scavenging activities}

To preliminarily compare the bioactive constituents in different samples, TLC autograph analysis was performed for four samples with significant activity and low toxicity. This yielded the identification of four samples with a richness of different components, including F-7-1-c (from Talaromyces sp. C21-1), F-11-1-b (from Aspergillus terreus C23-3), F-16-1-b (from Trichoderma harzianum DLEN2008005) 
and F-24-1-b (from Penicillium corylophilum TBG1-17). Among these, the AChE inhibitory activity and DPPH free radical scavenging activity of F-11-1-b (marked with red frame in Supplementary Fig. S2) were both significant. Thus, its active components were further analyzed by LC-MS/MS coupled with bioactivity.

\section{Bioactivity coupled LC-MS/MS analyses and molecular networking}

To localize the active molecules in sample F-11-1-b, it was incubated with AChE in an ultrafiltration-LC-MS/MS experiment and with DPPH in antioxidant coupled LC-MS/ MS experiment. The bioactive molecules were recognized by comparison of corresponding peak area in the control experiment (sample non-specifically captured by ultrafiltration membrane) vs co-incubation experiment (sample captured by $\mathrm{AChE}$ and by ultrafiltration membrane) or the peak area in sample control vs in co-incubation experiment (sample totally or partially consumed by DPPH). However, to avoid inaccuracies caused by directly using the peak area from the total ion chromatograms (TIC) or base peak chromatograms (BPC) due to overlapping peaks, we compared the peak areas of the extracted ion chromatograms (EIC) for the parent ions of the main peaks from the BPC.
As shown in Fig. 2 and Table 2, five parent ions at $\mathrm{m} / \mathrm{z}$ 513.00-513.30 (1), m/z 497.15-497.25 (2), m/z $527.00-527.30(3), \mathrm{m} / \mathrm{z} 553.00-553.40(4)$, and $\mathrm{m} / \mathrm{z}$ 511.00-511.40 (5) demonstrated higher integral areas in the experimental group (sample \& AChE-Ultrafiltration) than in the control group (sample-Ultrafiltration), indicating that they are specifically captured by the enzyme. Especially for compounds $\mathbf{4}$ and $\mathbf{5}$, their selective binding rates reached $27.5 \%$ and $73.7 \%$, which suggested that they were possibly the main AChE inhibitors in this sample. The peak area of another parent ion at $\mathrm{m} / \mathrm{z}$ 549.00-549.30 (the 'control peak') showed little change between the two experiments, indicating the changes of other peaks were not false positives.

As shown in Fig. 3 and Table 3, seven parent ions at $\mathrm{m} / \mathrm{z} 422.90-423.20(6), \mathrm{m} / \mathrm{z} 424.80-425.10$ (7), $\mathrm{m} / \mathrm{z}$ 607.10-607.40 (8), m/z 663.30-663.60(9), m/z $775.80-776.10(\mathbf{1 0}), \mathrm{m} / \mathrm{z}$ 370.60-371.00 (11), and $\mathrm{m} / \mathrm{z}$ 444.80-445.10 (12) exhibited much lower peak areas in the experimental group (sample \& DPPH) than in the control group (sample) with rates of consumption from $47.4-100 \%$, suggesting that they are the main antioxidative molecules in this sample. The parent ion at $\mathrm{m} / \mathrm{z} 416.00-416.30$ was taken as the control peak because it changed very little between experiments.

To obtain more information on the structures and relationship of these bioactive molecules, the LC-MS/MS
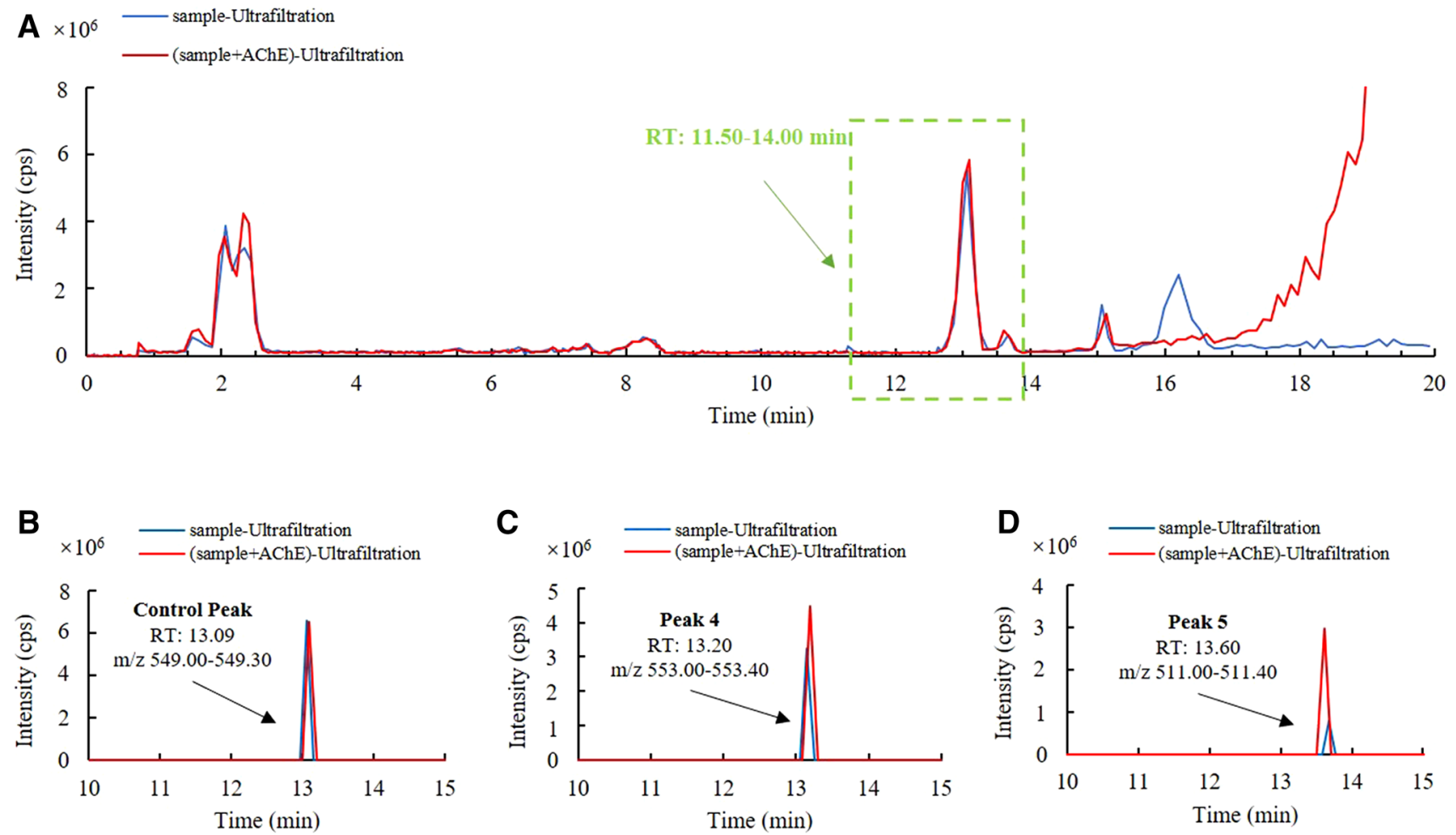

Fig. 2 Base peak chromatogram of F-11-1-b (A) and extracted ion chromatograms of control peak (B) and representative active peaks (C, D) 
Table 2 List of compounds with AChE inhibitory activity

\begin{tabular}{|c|c|c|c|c|c|}
\hline Activity compounds & $\begin{array}{l}\text { Apex RT } \\
(\min )\end{array}$ & $\mathrm{m} / \mathrm{z}$ & $\begin{array}{l}\text { Peak area in sample-Ultra- } \\
\text { filtration }\left(\mathrm{PA}_{\mathrm{SU}}\right)\end{array}$ & $\begin{array}{l}\text { Peak area in Sample\&AChE- } \\
\text { Ultrafiltration }\left(\mathrm{PA}_{\mathrm{SAU}}\right)\end{array}$ & $\begin{array}{l}\text { Selective bind- } \\
\text { ing rates }{ }^{\mathrm{a}}(\%)\end{array}$ \\
\hline 1 & 6.96 & $513.00-513.30$ & $4,596,241.43$ & $4,779,726.54$ & 3.8 \\
\hline 2 & 11.44 & $497.15-497.25$ & $381,901.19$ & $406,943.11$ & 6.2 \\
\hline 3 & 13.06 & $527.00-527.30$ & $83,466,812.45$ & $91,603,254.52$ & 8.9 \\
\hline 4 & 13.20 & $553.00-553.40$ & $3,250,644.83$ & $4,486,272.20$ & 27.5 \\
\hline 5 & 13.60 & $511.00-511.40$ & $785,028.42$ & $2,982,248.93$ & 73.7 \\
\hline Control peak & 13.09 & $549.00-549.30$ & $6,581,207.55$ & $6,522,441.10$ & -0.9 \\
\hline
\end{tabular}

${ }^{\mathrm{a}}$ Selective binding rate $(\%)=100 *\left(\mathrm{PA}_{\mathrm{SAU}}-\mathrm{PA}_{\mathrm{SU}}\right) / \mathrm{PA}_{\mathrm{SAU}}$

data of sample F-11-1-b were submitted to the GNPS platform for molecular networking. In the network (Fig. 4), compounds 1-5 were in the same cluster suggesting that they were structurally related. Compound $\mathbf{3}$ gave $\mathrm{MS}^{2}$ fragment ions at $\mathrm{m} / \mathrm{z} 509.00,491.01,473.20$, $373.00,291.10,195.07$, which matched territrem B in the GNPS database with a cosine value of 0.94 . Considering Aspergillus terreus was frequently reported as a producer of this AChE inhibitor (Nong et al. 2014; Peng 1995), compound $\mathbf{3}$ was annotated as territrem B. Compared with compound $\mathbf{3}$, both the parent ion and a series of fragment ions deriving from compound $\mathbf{1}$ showed a mass difference of $-14 \mathrm{Da}\left(-\mathrm{CH}_{2}\right)$. Similarly, compound 2 decreased by
$30 \mathrm{Da}\left(-\mathrm{CH}_{2} \mathrm{O}\right)$ compared to compound $\mathbf{3}$, and those of compound 5 decreased by $16 \mathrm{Da}\left(-\mathrm{CH}_{4}\right.$ or $\left.-\mathrm{O}\right)$. According to their MS characteristics and the MS data recorded in literature, the known territrem analogs for compounds $\mathbf{1 , 2}$, and $\mathbf{5}$ were possibly territrem C (or D), arisugacin A and territrem A, respectively (Jiang et al. 2010; Lee et al. 1992). However, other isomers are also possible based on these mass spectra.

The parent ion of compound $\mathbf{4}$ showed a mass difference of +26 Da compared with territrem B (3), and the $\mathrm{MS}^{2}$ fragments ion were at $\mathrm{m} / \mathrm{z} 535.06,509.00,491.01,473.20$, 291.10, 195.07; thus, it was determined that compound 4 was a dehydrogenated territrem analog with two more
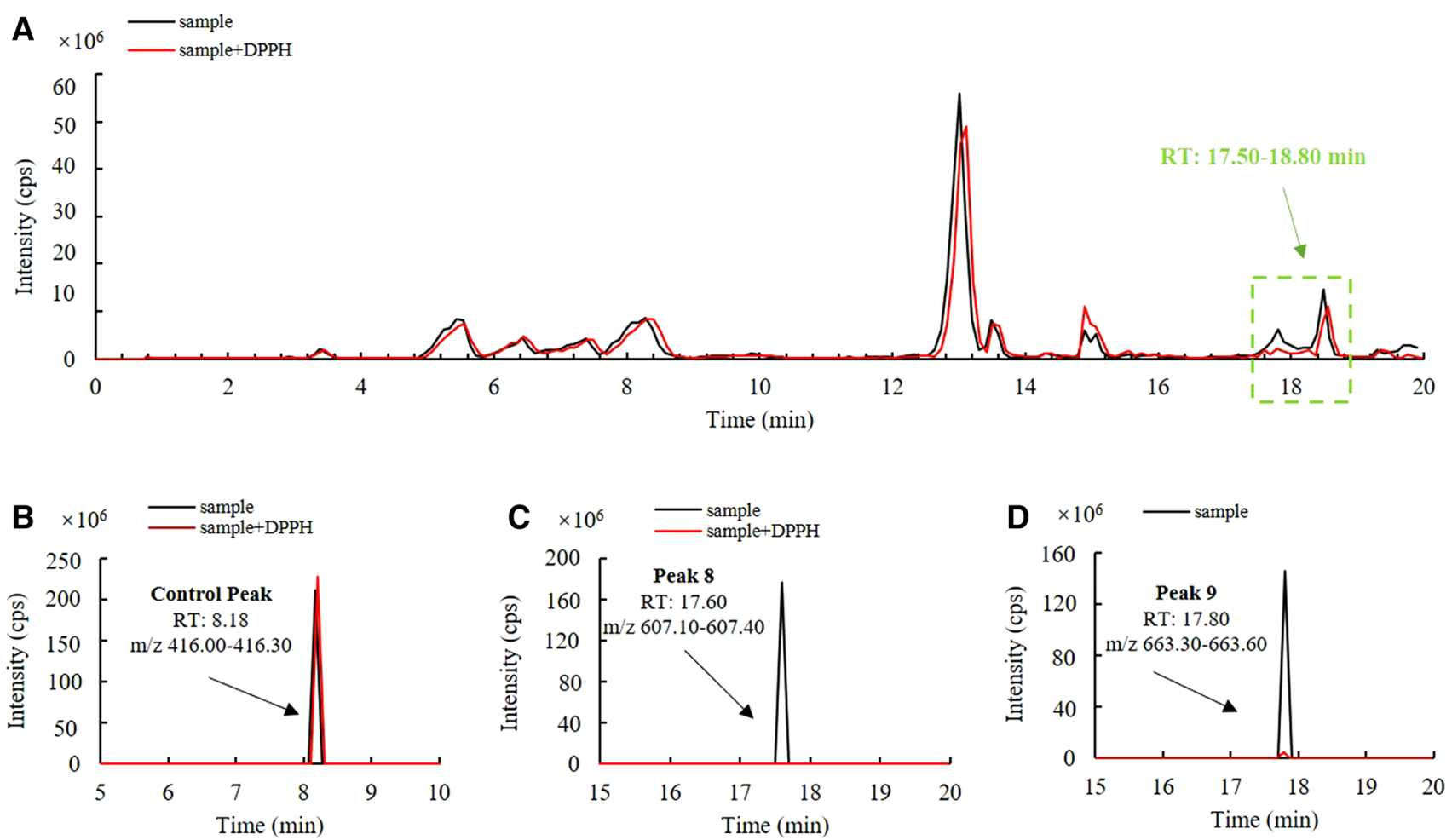

Fig. 3 Base peak chromatogram of F-11-1-b (A) and extracted ion chromatograms of control peak (B) and representative active peaks (C, D) 
Table 3 List of compounds with DPPH free radical scavenging activity

\begin{tabular}{|c|c|c|c|c|c|}
\hline Activity compounds & Apex RT (min) & $\mathrm{m} / \mathrm{z}$ & Peak area in sample $\left(\mathrm{PA}_{\mathrm{S}}\right)$ & $\begin{array}{l}\text { Peak area in sam- } \\
\text { ple + DPPH }\left(\mathrm{PA}_{\mathrm{SD}}\right)\end{array}$ & $\begin{array}{l}\text { Rate of } \\
\text { consumption } \\
(\%)\end{array}$ \\
\hline 6 & 5.44 & $422.90-423.20$ & $26,405,303.75$ & $13,820,561.89$ & 47.7 \\
\hline 7 & 12.40 & $424.80-425.10$ & $26,618,184.14$ & $11,323,916.92$ & 57.5 \\
\hline 8 & 17.60 & $607.10-607.40$ & $17,642,213.29$ & 0.00 & 100.0 \\
\hline 9 & 17.80 & $663.30-663.60$ & $146,027,066.28$ & $4,539,348.93$ & 96.9 \\
\hline 10 & 17.80 & $775.80-776.10$ & $26,772,043.07$ & $10,915,961.28$ & 59.2 \\
\hline 11 & 17.90 & $370.60-371.00$ & $41,469,935.86$ & $16,864,824.46$ & 59.3 \\
\hline 12 & 18.07 & $444.80-445.10$ & $35,592,992.49$ & $18,346,767.04$ & 48.5 \\
\hline Control peak & 8.18 & $416.00-416.30$ & $211,489,153.70$ & $227,538,708.80$ & -7.6 \\
\hline
\end{tabular}

${ }^{a}$ Rate of consumption $(\%)=100 *\left(\mathrm{PA}_{\mathrm{S}}-\mathrm{PA}_{\mathrm{SD}}\right) / \mathrm{PA}_{\mathrm{S}}$

methyl groups or one more carbonyl than territrem $\mathrm{B}(\mathbf{3})$. Thus, its molecular formula is either $\mathrm{C}_{31} \mathrm{H}_{36} \mathrm{O}_{9}$ or $\mathrm{C}_{30} \mathrm{H}_{32} \mathrm{O}_{10}$. A search of Scifinder indicated that there were no known territrem-like structures among the 148 records for $\mathrm{C}_{31} \mathrm{H}_{36} \mathrm{O}_{9}$ and the 108 records for $\mathrm{C}_{30} \mathrm{H}_{32} \mathrm{O}_{10}$. Therefore, compound 4 is very likely a new compound.

For the antioxidative molecules, compound 7 with a parent mass at $\mathrm{m} / \mathrm{z} 424.97$ was annotated as butyrolactone I by GNPS molecular library matching with a cosine value of 0.93, while compound 6 at $\mathrm{m} / \mathrm{z} 423.03$ in the same cluster was its dehydrogenated analog, matching the structure of aspernolide E in the Dictionary of Natural Products (https ://dnp.chemnetbase.com) (He et al. 2013).

The potent antioxidants $\mathbf{8}$ and $\mathbf{9}$, present in the same cluster, may be long-chain lipids because 8 (at $\mathrm{m} / \mathrm{z}$ 607.36) shared a mutual strong fragment at $\mathrm{m} / \mathrm{z} 551.25-551.47$ and a moderately similar $\mathrm{MS}^{2}$ pattern (cosine value 0.74 ) to a phospholipid (CCMSLIB00000078672 in GNPS library) with a significantly higher parent mass ( $\mathrm{m} / \mathrm{z}$ 692.40).

By GNPS analysis, compound $\mathbf{1 1}$ displayed similarity with a phenolic compound methyl 2-(2,6-dihydroxy-4-methylbenzoyl)-3,5-dimethoxybenzoate (CCMSLIB00004686882) with a cosine value of 0.72 and the same molecular weight. For compounds $\mathbf{1 0}$ and 12, GNPS gave no matching hits.

Summarizing, compounds 4, 8-10 and $\mathbf{1 2}$ have a high possibility of being bioactive compounds with new structures, and this will be confirmed by ongoing investigations.

\section{Discussion}

Marine fungi can be important resources for anti-AChE and antioxidant molecules. Quite a few important AChE inhibitors have been reported from species like Xylaria sp., Aspergillus terreus, Talaromyces sp., Arthrinium arundinis, Asp. unguis, Acrostalagmus luteoalbus (Lin et al. 2001; Nong et al. 2014; Wu et al. 2015; Zhang et al. 2019), etc., together with strong antioxidants from Asp. terreus, Asp. wentii, Penicillium solitum, Xylaria sp. (Gong et al. 2018; Guo et al. 2015; Li et al. 2014; Zhu et al. 2014). In the present study, Asp. terreus and Talaromyces sp. were also found to be producers of AChE inhibitors and/or antioxidants. Strains belonging to Neosartorya glabra, Hypocreaceae, Penicillium sp., P. glabrum, P. corylophilum, Trichoderma harzianum, and Tritirachium sp. also showed strong anti-AChE potential. Strains of Asp. flavipes, Hypocreaceae, Sterigmocystis sp., P. digitatum, Hypocrea lixii, P. polonicum, P. chrysogenum, and $P$. corylophilum exhibited antioxidant capability. Most of these taxa have seldom been reported to possess natural products with these activities, and thus they may be new resources for valuable lead molecules.

In particular, 20 bioactive fractions from 12 strains including Talaromyces sp. C21-1, Asp. terreus C23-3, Trichoderma harzianum DLEN2008005 and P. corylophilum TBG1-17 with diverse bioactive constituents also displayed low toxicity to Artemia larvae, suggesting they may be valuable in anti-AD drug discovery. The Artemia lethality model has been frequently used for screening cytotoxic and pesticidal agents due to its good correlation, low cost and convenience (Badisa et al. 2009; Cheng et al. 2003; Zhang et al. 2012, 2013). In this investigation, it was used as a toxicity evaluation approach. As for AChE inhibitory samples, if they did not show significant toxicity to Artemia larvae, then they are more likely to be reversible AChE inhibitors with anti-AD potential rather than irreversible ones, the latter being preferred in pesticide discovery.

In our work, before bioactivity coupled LC-MS/MS analysis, we performed a preliminary assessment via TLC autography for surveying the diversity of bioactive components in different samples. This method is not as highresolution and informative as bioactivity coupled LC-MS/ MS; however, it has the advantage of high efficiency, lower cost, and intuition. 


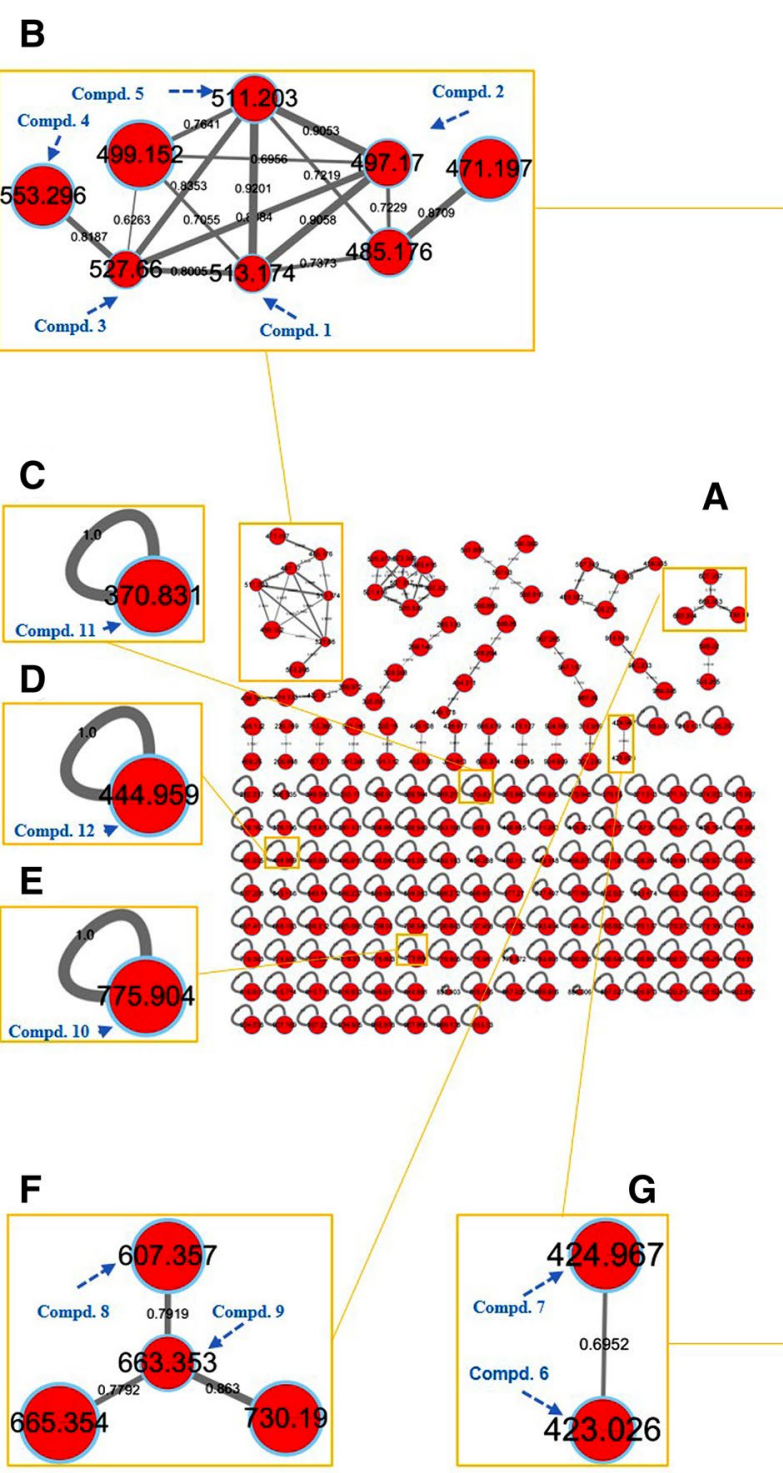

Fig. 4 Molecular networking of F-11-1-b. A Molecular networking of the organic extract from F-11-1-b. B-G Clusters corresponding to compounds 1-12 observed by molecular networking. H Plausible

For the discovery of bioactive natural products, it is typical to use a chemistry-guided or bioactivity-guided isolation strategy. Nevertheless, traditional chemical separation is a blind process and the conventional offline bioactivity tracing is inefficient, often leading to repeated isolation of known compounds. Hence, it is necessary to localize bioactive molecules and obtain as much structural information as possible to increase the probability of finding new compounds before the significant effort is put into compound
H

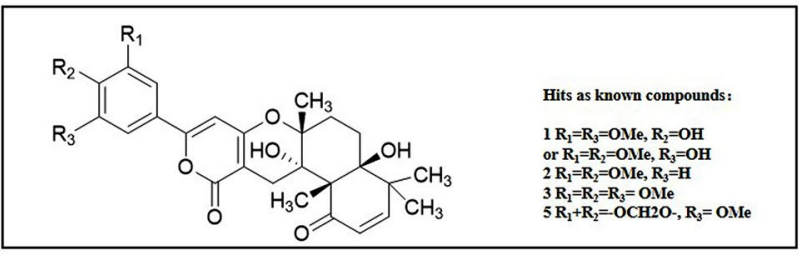

I

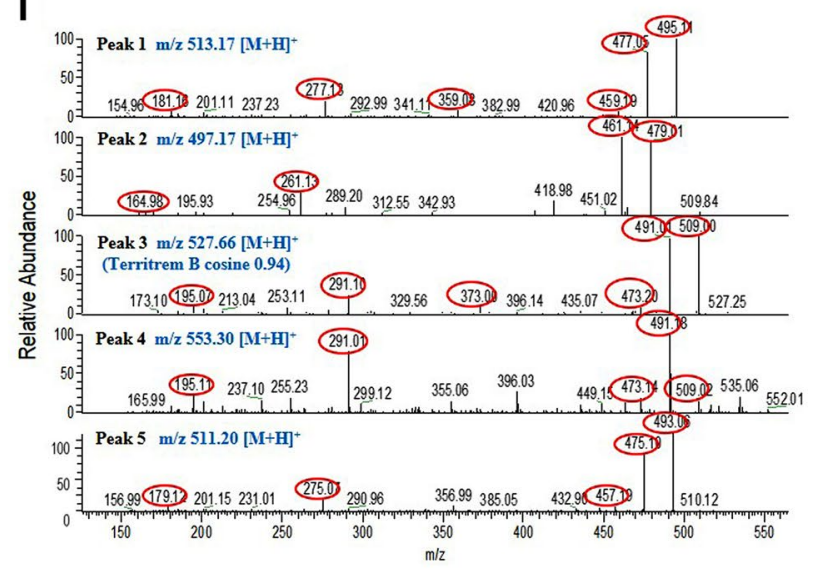

$\mathbf{J}$

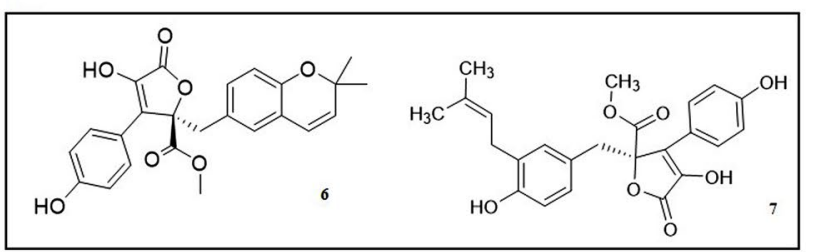

K

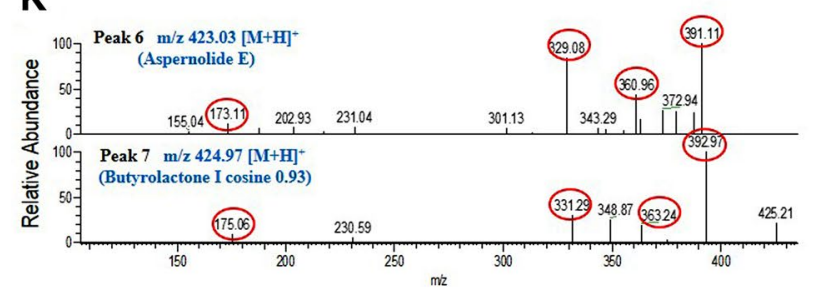

chemical structures of 1-3 and 5. I MS/MS spectrum of the 1-5. JK Plausible chemical structures and MS/MS spectra of 6-7

isolation. By the strategy of combining bioactivity coupled LC-MS/MS analysis and GNPS molecular networking in the present study, we have accelerated this process. In the current study, using this integrated strategy, we were able to annotate five territrem derivatives as $\mathrm{AChE}$ inhibitors while two aromatic butyrolactones and five other metabolites were assigned as antioxidants. Moreover, five of the described molecules have a high possibility of being new compounds or new metabolites from Asp. terreus. This latter conclusion 
requires confirmation through further investigation that will require chromatography and spectroscopic experiments. Summarizing, this new integrated strategy provided a significant amount of useful information and identified key new products for further study.

The robustness of assessing novelty by this methodology is to a great extent influenced by the size of the compound MS/MS database. Up until now, GNPS has deposited the MS/MS spectra of more than 150,000 natural products (as of 2020-04-13) from contributors all over the world and from the third party MS/MS libraries like NIST, Massbank and HMDB. While a large number, this is certainly a limitation compared to the number of all known metabolites. However, the continued increase of GNPS data will improve the effectiveness of our Bio-LC-MS/MS coupled GNPS strategy in the future.

In conclusion, by a combined bioactivity-toxicity model, 20 fractionated extracts from diverse and previously less studied marine fungal taxa were assessed for their AChE inhibitory and/or antioxidant potential together with low Artemia toxicity. TLC autographies and Bio-LC-MS/MS coupled GNPS localized bioactive molecules and provided rich structural information including indications of likely new bioactive compounds for further study. This strategy could be useful for discovering new anti-Alzheimer lead compounds from the sea.

\section{Materials and methods}

\section{Materials}

The 35 strains of marine fungi used in this study were from biological samples collected in the intertidal zone of Dalian China (Zhang et al. 2009), gill tissues from sharks captured in the East China Sea (Zhang et al. 2016), and different corals in the Zhanjiang sea area of China, as shown in Table 4.

\section{Preparation of samples of secondary metabolites of marine fungi}

The 3-5 day agar plates of the strains were used to inoculate Erlenmeyer flasks each containing $200 \mathrm{ml}$ potato sucrose peptone liquid medium (PSP, containing boiled juice from $200 \mathrm{~g}$ potato per liter, $20 \mathrm{~g} / \mathrm{L}$ sucrose, $5 \mathrm{~g} / \mathrm{L}$ peptone, and $20 \mathrm{~g} / \mathrm{L}$ sea salt) or malt extract liquid medium (M, containing $15 \mathrm{~g} / \mathrm{L}$ malt extract, $20 \mathrm{~g} / \mathrm{L}$ sea salt), respectively. Both media were used for each strain. The static fermentation lasted for 20 days at room temperature (about $28^{\circ} \mathrm{C}$ ). Afterwards, the fermentation broth was extracted using ethyl acetate and the mycelia were extracted using methanol. The two extracts for each sample were combined and concentrated to dryness using a rotary evaporator at $45{ }^{\circ} \mathrm{C}$. Then, each crude extract was mixed with silica gel, applied to a short silica gel flash column and stepwise eluted with n-hexane, dichloromethane, ethyl acetate, and methanol to yield four fractional samples.

\section{The screening of AChE inhibitory activity and antioxidant activity}

Samples were first preliminarily screened for the two activities on TLC plates by array autography. In this experiment, the samples $(20 \mu \mathrm{g}$ for each) were applied onto grids $(1 \mathrm{~cm} \times 1 \mathrm{~cm})$ on the $\mathrm{GF}_{254} \mathrm{TLC}$ plates with a capillary tube. For autography of AChE inhibition, the plate was first evenly sprayed with $0.5 \mathrm{U} / \mathrm{ml} \mathrm{AChE}$ solution, air dried to fix the enzyme, and then the plates were kept in an incubator with constant moisture at $37^{\circ} \mathrm{C}$ for $20 \mathrm{~min}$. Afterwards, DTNB $(5 \mathrm{mmol} / \mathrm{L})$ and ATCh $(10 \mathrm{mmol} / \mathrm{L})$ solutions were mixed $(1: 1, v / v)$ and sprayed onto the TLC plates. These were incubated for another $10 \mathrm{~min}$ and the results were recorded. The active spots were white on a yellow background. For autography of DPPH scavenging activity, DPPH methanol solution $(1.28 \mathrm{mmol} / \mathrm{L})$ was sprayed evenly on the TLC plates containing the samples, and the results were observed after keeping the plates in darkness for 5-8 min. The active spots had no color and contrasted to a purple background.

The positive samples from the above screening program were then quantitatively evaluated for inhibition to $\mathrm{AChE}$ or DPPH scavenging rates at a dose of $200 \mu \mathrm{g} / \mathrm{ml}$ using 96-well microplates by a previously reported method (Yang et al. 2018). Each sample was tested in duplicate and the averages were calculated. Tacrine and vitamin $\mathrm{C}$ were taken as positive controls for the AChE experiment and DPPH experiments, respectively.

\section{Toxicity determination of active samples}

Artemia toxicity was determined for samples with an AChE inhibition rate and/or a DPPH radical scavenging rate $\geq 50 \%$. The final concentration of samples was $50 \mu \mathrm{g} / \mathrm{ml}$ and the larval number per assay was $20-30 /$ well in 48-well microplates. $\mathrm{CuSO}_{4}(50 \mu \mathrm{g} / \mathrm{ml})$ was used as positive control. Each sample was tested in triplicate and the average was calculated. The experiment and lethality rate calculations were performed following a previously reported method (Kiviranta et al. 2010).

\section{TLC-activity autograph analyses}

The samples with high activity and low toxicity were compared for their diversity of active components by TLC autography. The samples were first applied onto 
Table 4 List of marine fungal strains tested

\begin{tabular}{|c|c|c|c|c|}
\hline $\begin{array}{l}\text { Sequence } \\
\text { number }\end{array}$ & Strain number & Species & GenBank serial number & Source \\
\hline 1 & BP1T8 & Penicillium polonicum & JF731253 & Shark gill \\
\hline 2 & BP2T1 & Penicillium chrysogenum & JF731254 & Shark gill \\
\hline 3 & ВCT1-7 & Aspergillus sydowii & JF731252 & Shark gill \\
\hline 4 & ВCT2-3 & Aspergillus flavipes & JQ082507 & Shark gill \\
\hline 5 & BM3T2 & Neosartorya glabra & JQ082501 & Shark gill \\
\hline 6 & BM3T6 & Aspergillus sydowii & JN368457 & Shark gill \\
\hline 7 & $\mathrm{C} 21-1$ & Talaromyces sp. & $-^{\mathrm{a}}$ & Porites pukoensis \\
\hline 8 & $\mathrm{C} 2-4$ & Aspergillus sp. & JQ717350 & Porites compressa \\
\hline 9 & $\mathrm{C} 22-4$ & unclassified & - & Porites compressa \\
\hline 10 & $\mathrm{C} 3-1$ & Hypocreaceae sp. & JQ717351 & Pavona cactus \\
\hline 11 & $\mathrm{C} 23-3$ & Aspergillus terreus & MG707631 & Pavona cactus \\
\hline 12 & C3-6 & Penicillium sp. & JQ717353 & Pavona cactus \\
\hline 13 & C3-18 & Sterigmocystis & $-^{\mathrm{a}}$ & Pavona cactus \\
\hline 14 & $\mathrm{C} 23-18$ & Penicilium digitatum & $-^{\mathrm{a}}$ & Pavona cactus \\
\hline 15 & DLEP2008001 & Aspergillus unguis & GU117635 & Seaweed \\
\hline 16 & DLEN2008005 & Trichoderma harzianum & KU530201 & Seaweed \\
\hline 17 & DLEN2008006 & Aspergillus clavatus & GU266275 & Spongia \\
\hline 18 & DLEN2008010 & Hypocrea lixii & HQ149775 & Spongia \\
\hline 19 & DLEN2008016 & Penicillium glabrum & FJ618520 & Seaweed \\
\hline 20 & TBG1-6 & Penicillium polonicum & JF731267 & Shark gill \\
\hline 21 & TBG1-12 & Penicillium chrysogenum & JF731261 & Shark gill \\
\hline 22 & TBG1-13 & unclassified & - & Shark gill \\
\hline 23 & TBG1-14 & Penicillium corylophilum & JQ082506 & Shark gill \\
\hline 24 & TBG1-17 & Penicillium corylophilum & JQ082502 & Shark gill \\
\hline 25 & TBG1-19 & unclassified & - & Shark gill \\
\hline 26 & TBG1-21 & Penicillium sp. & KF746907 & Shark gill \\
\hline 27 & TBG2-6 & unclassified & - & Shark gill \\
\hline 28 & TBG3-10 & Penicillium crustosum & JF731272 & Shark gill \\
\hline 29 & TBG3-17 & unclassified & - & Shark gill \\
\hline 30 & TBG3-21 & Penicillium commune & JQ082505 & Shark gill \\
\hline 31 & TBG3-19-2 & Penicillium chrysogenum & JQ082504 & Shark gill \\
\hline 32 & $19-10-1$ & Aspergillus fumigatus & HQ149777 & Sebastodes sp. gill \\
\hline 33 & $\mathrm{C} 22-2$ & Tritirachium sp. & JQ717341 & Porites compressa \\
\hline 34 & C2-9 & Gibberella moniliformis & JQ717335 & Porites compressa \\
\hline 35 & $\mathrm{C} 2-19$ & Penicillium funiculosum & JQ717333 & Porites compressa \\
\hline
\end{tabular}

${ }^{a}-$ : morphologically authenticated
TLC plates, developed with an organic solvent system (chloroform: methanol $=25: 1(\mathrm{v} / \mathrm{v})$ for $\mathrm{n}$-hexane eluted fractions; chloroform: $m e t h a n o l=5: 1(\mathrm{v} / \mathrm{v})$ for other fractions), dried, observed and photographed under wavelengths of 254 and $365 \mathrm{~nm}$. Then, the bioactive spots were demonstrated using the same colorimetric methods described above in the screening by autography section.

\section{Bioactivity coupled HPLC-MS/MS analyses}

Pretreatment of AChE coupled ultrafiltration-LC-MS/MS analysis: in the treatment group, the sample was first incubated with $\mathrm{AChE}$ (final concentration: $0.5 \mathrm{mg} / \mathrm{ml}$ for sample and $0.2 \mathrm{U} / \mathrm{ml}$ for enzyme) in $100 \mu \mathrm{l}$ phosphate buffer solution (PBS) containing $15 \% \mathrm{MeOH}$ in a water bath at $37{ }^{\circ} \mathrm{C}$ for $30 \mathrm{~min}$. Then, the mixture was transferred into an ultrafiltration (UF) centrifugal tube (UFC510096 Millipore 100 $\mathrm{KD}$ ) and centrifuged at $12,000 \mathrm{r} / \mathrm{min}$ for $20 \mathrm{~min}$ to capture the AChE-ligand complex. The UF membrane loaded with 
this complex was rinsed and centrifuged with PBS (100 $\mu$ l, three times). Afterwards, 50\% aqueous $\mathrm{MeOH}(100 \mu 1$, three times) was added to the membrane to release the small molecule ligands from the complex, followed by centrifugation. The filtrate was concentrated to dryness and finally resolved in $100 \mu \mathrm{l} 50 \%$ aqueous $\mathrm{MeOH}$ for LC-MS/MS analysis. In the blank group, the sample was directly dissolved in $100 \mu \mathrm{l}$ $50 \%$ aqueous $\mathrm{MeOH}$. In the control group, the sample was incubated in PBS-MeOH solution without AChE, and the other procedures were the same with the treatment group. The injection volumes of the three groups were all $25 \mu \mathrm{l}$ for the next step of LC-MS/MS analysis.

Pretreatment of DPPH radical scavenging activity coupled LC-MS/MS analysis: in the treatment group, the samples $(50 \mu 11.0 \mathrm{mg} / \mathrm{ml}$ dissolved in methanol) reacted with DPPH methanol solution $(50 \mu 1,0.16 \mathrm{mmol} / \mathrm{L})$ for $30 \mathrm{~min}$ in darkness. In the control group, the DPPH solution was replaced by the same amount of methanol. In the blank group, $0.08 \mathrm{mmol} / \mathrm{L}$ DPPH solution was directly used as a sample for LC-MS/MS. The injection volumes of the three groups were all $25 \mu \mathrm{l}$ in LC-MS/MS analysis.

All nominal mass resolution LC-MS/MS analyses were run on a LC-PDA-MS ${ }^{2}$ system consisting of Thermo Finnigan Surveyor Autosampler-Plus, LC-Pump-Plus, PDAPlus, and a Thermo Finnigan LCQ Advantage Plus mass spectrometer. The monitoring wavelength and mass scan range were set to be 190-600 $\mathrm{nm}$ and $\mathrm{m} / \mathrm{z} 100-2000$ in the positive mode (the unified mode for GNPS molecular networking), respectively. The column was a Phenomenex Kinetex C18 100A reverse phase column $(100 \times 4.60 \mathrm{~mm}$, $5 \mu \mathrm{m})$. The flow rate was $0.6 \mathrm{ml} / \mathrm{min}$ and a gradient program of $\mathrm{CH}_{3} \mathrm{CN} / \mathrm{H}_{2} \mathrm{O}(0.1 \%$ formic acid) was used for elution: 0-8 $\min$ for $40 \%, 8-11 \mathrm{~min}$ for 40 to $99 \%, 11-16 \mathrm{~min}$ for $99 \%, 16-16.2 \mathrm{~min}$ for 99 to $40 \%, 16.2-20 \mathrm{~min}$ for $40 \%$.

The MS/MS spectra of sample F-11-1-b were used to establish a molecular network using the GNPS online platform and visualized by Cytoscape 3.7 software for the purpose of molecular networking and dereplication. The 'Default Molecular Networking Results views' and 'Molecular-library search functions' were used to search hits for possible known compounds. The raw data have been deposited in the MassIVE database at the GNPS Web site (https ://gnps.ucsd.edu/ProteoSAFe/static/gnps-splash.jsp) and is publicly available through access number MSV000085297.

Acknowledgements This work was supported by the Yangfan Talent Project of Guangdong Province under Grant 201433009; the Natural Science Foundation of Guangdong Province under Grant 2018A030307046; the Basic Research Project of Shenzhen Science and Technology Innovation Commission under Grant JCYJ20190813105005619; the Shenzhen Dapeng New District Industrial Development Fund under Grants KY20180203 \& PT20190105; the Shenzhen Dapeng New District Scientific and Technological Research and Development Fund under Grant KJYF202001-07; the Natural Science Foundation of China under Grant 21807015; the Program for Scientific Research Start-Up Funds of Guangdong Ocean University under Grant E15155; the Applied S \& T Research and Development Major Project of Guangdong Province under Grant 2016B020235001; and the Scientific Fund of the Zhanjiang Municipal Oceanic and Fishery Bureau under Grant A18018; the Project of Enhancing School with Innovation of Guangdong Ocean University (230420022). We also thank E. Glukhov and L. Gerwick for helpful discussions (Scripps Institution of Oceanography, University of California, San Diego).

Author contributions YYN, WCY, YYL, JMY, and XLL performed the experiments. YYN wrote the paper. YZ conceived, designed, and supervised the experiments. YZ and WHG revised the manuscript. All authors have read and approved the submitted manuscript.

\section{Compliance with ethical standards}

Conflict of interest The authors declare no conflict of interest.

Animal and human rights statement This article does not contain any studies with human participants or animals performed.

Open Access This article is licensed under a Creative Commons Attribution 4.0 International License, which permits use, sharing, adaptation, distribution and reproduction in any medium or format, as long as you give appropriate credit to the original author(s) and the source, provide a link to the Creative Commons licence, and indicate if changes were made. The images or other third party material in this article are included in the article's Creative Commons licence, unless indicated otherwise in a credit line to the material. If material is not included in the article's Creative Commons licence and your intended use is not permitted by statutory regulation or exceeds the permitted use, you will need to obtain permission directly from the copyright holder. To view a copy of this licence, visit http://creativecommons.org/licenses/by/4.0/.

\section{References}

Allard PM, Péresse T, Bisson J, Gindro K, Marcourt L, Pham VC, Roussi F, Litaudon M, Wolfender JL (2016) Integration of molecular networking and in-silico MS/MS fragmentation for natural products dereplication. Anal Chem 88:3317-3323

Badisa RB, Darling-Reed SF, Joseph P, Cooperwood JS, Latinwo LM, Goodman CB (2009) Selective cytotoxic activities of two novel synthetic drugs on human breast carcinoma MCF-7 cells. Anticancer Res 29:2993-2996

Boer ARD, Lingeman H, Niessen WMA, Irth H (2007) Mass spectrometry-based biochemical assays for enzyme inhibitor screening. Trends Anal Chem 26:867-883

Butterfield DA, Hensley K, Polidori MC, Mariani E, Mecocci P (2008) Antioxidant agents in Alzheimer's disease. Cent Nerv Syst Agents Med Chem 8:48-63

Chen J, Zhao H, Shi Q, Zhang D, Lee SC (2010) Rapid screening and identification of the antioxidants in Hippocampus japonicus Kaup by HPLC-ESI-TOF/MS and on-line ABTS free radical scavenging assay. J Sep Sci 33:672-677

Cheng SS, Chang HT, Chang ST, Tsai KH, Chen WJ (2003) Bioactivity of selected plant essential oils against the yellow fever mosquito Aedes aegypti larvae. Bioresour Technol 89:99-102

Crawley JN (1993) Functional interactions of galanin and acetylcholine: relevance to memory and Alzheimer's disease. Behav Brain Res 57:133-141 
Goedert M (1993) Tau protein and the neurofibrillary pathology of Alzheimer's disease. Trends Neurosci 16:460-465

Gong HF, Luo ZW, Chen WL, Feng ZP, Wang GL (2018) Marine compound xyloketal B as a potential drug development target for neuroprotection. Mar Drugs 16:516

Guo W, Kong X, Zhu T, Gu Q, Li D (2015) Penipyrols A-B and peniamidones A-D from the mangrove derived Penicillium solitum GWQ-143. Arch Pharm Res 38:1449-1454

Haass C, Selkoe DJ (1993) Cellular processing of $\beta$-amyloid precursor protein and the genesis of amyloid $\beta$-peptide. Cell 75:1039-1042

He F, Bao J, Zhang XY, Tu ZC, Shi YM, Qi SH (2013) Asperterrestide A, a cytotoxic cyclic tetrapeptide from the marine-derived fungus Aspergillus terreus SCSGAF0162. J Nat Prod 76:1182-1186

Ji NY, Wang BG (2016) Mycochemistry of marine algicolous fungi. Fungal Divers 80:301-342

Jiang XR, Lei A, Zhou CX, Yang LX, Zhang QJ, Li HB, Sun LL, Wu XM, Hua B, Yu Z (2010) Design, synthesis, and biological evaluation of new territrem $B$ analogues. Chem Biodivers 2:557-567

Jin LM, Quan CS, Hou XY, Fan SD (2016) Potential pharmacological resources: natural bioactive compounds from marine-derived fungi. Mar Drugs 14:76

Kiviranta J, Sivonen K, Niemelä SI, Huovinen K (2010) Detection of toxicity of cyanobacteria by Artemia salina bioassay. Environ Toxicol 6:423-436

Kok PL, Shan HH, Ranil DS, Benny HT, Yi ZZ (2006) Oxidative stress: apoptosis in neuronal injury. Curr Alzheimer Res 3:327-337

Lee SS, Peng FC, Chiou CM, Ling KH (1992) NMR assignments of territrems $\mathrm{A}, \mathrm{B}$, and $\mathrm{C}$ and the structure of $\mathrm{MB} 2$, the major metabolite of territrem B by rat liver microsomal fraction. J Nat Prod 55:251-255

Li X, Li X, Xu G-M, Li C-S, Wang B-G (2014) Antioxidant metabolites from marine alga-derived fungus Aspergillus wentii EN-48. Phytochem Lett 7:120-123

Lin Y, Wu X, Feng S, Jiang G, Luo J, Zhou S, Vrijmoed LL, Jones EB, Krohn K, Steingrover K, Zsila F (2001) Five unique compounds: xyloketals from mangrove fungus Xylaria sp. from the South China Sea coast. J Org Chem 66:6252-6256

Liu L, Zheng YY, Shao CL, Wang CY (2019) Metabolites from marine invertebrates and their symbiotic microorganisms: molecular diversity discovery, mining, and application. Mar Life Sci Technol 1:60-94

Mcgleenon BM, Dynan KB, Passmore AP (1999) Acetylcholinesterase inhibitors in Alzheimer's disease. Br J Clin Pharmacol 48:471-480

Mehta M, Adem A, Sabbagh M (2012) New acetylcholinesterase inhibitors for Alzheimer's disease. Int J Alzheimers Dis 2012:728983

Nong XH, Wang YF, Zhang XY, Zhou MP, Xu XY, Qi SH (2014) Territrem and butyrolactone derivatives from a marine-derived fungus Aspergillus terreus. Mar Drugs 12:6113-6124

Peng FC (1995) Acetylcholinesterase inhibition by territrem B derivatives. J Nat Prod 58:857-862

Rogers J, Webster S, Lue LF, Brachova L, Mcgeer P (1996) Inflammation and Alzheimer's disease pathogenesis. Neurobiol Aging $17: 681-686$
Scheff SW, Dekosky ST, Price DA (1990) Quantitative assessment of cortical synaptic density in Alzheimer's disease. Neurobiol Aging 11:29-37

Verbeek MM, Otte-Höller I, Westphal JR, Wesseling P, Waal RMWD (1994) Accumulation of intercellular adhesion molecule-1 in senile plaques in brain tissue of patients with Alzheimer's disease. Am J Pathol 144:104-116

Wang M, Carver JJ, Phelan VV, Sanchez LM, Garg N, Peng Y, Nguyen DD, Watrous J, Kapono CA, Luzzatto-Knaan T, Porto C, Bouslimani A, Melnik AV, Meehan MJ, Liu WT, Crusemann M, Boudreau PD, Esquenazi E, Sandoval-Calderon M, Kersten RD et al (2016) Sharing and community curation of mass spectrometry data with global natural products social molecular networking. Nat Biotechnol 34:828-837

Wilcock GK, Esiri MM (1982) Plaques, tangles and dementia: a quantitative study. J Neurol Sci 56:343-356

Wu B, Ohlendorf B, Oesker V, Wiese J, Malien S, Schmaljohann R, Imhoff JF (2015) Acetylcholinesterase inhibitors from a marine fungus Talaromyces sp. strain LF458. Mar Biotechnol 17:110-119

Yang WC, Bao HY, Liu YY, Nie YY, Yang JM, Hong PZ, Zhang Y (2018) Depsidone derivatives and a cyclopeptide produced by marine fungus Aspergillus unguis under chemical induction and by its plasma induced mutant. Molecules 23:2245

Ye F, Wang XC (2012) Antioxidant therapies for Alzheimer's disease. Oxid Med Cell Longev 2012:472932

Zhang Y, Mu J, Feng Y, Kang Y, Zhang J, Gu PJ, Wang Y, Ma LF, Zhu YH (2009) Broad-spectrum antimicrobial epiphytic and endophytic fungi from marine organisms: isolation, bioassay and taxonomy. Mar Drugs 7:97-112

Zhang Y, Mu J, Han J, Gu X (2012) An improved brine shrimp larvae lethality microwell test method. Toxicol Mech Methods 22:23-30

Zhang Y, Mu J, Feng Y, Li H, Dong X (2013) Biological and chemical diversity of cytotoxin-producing symbiotic marine fungi in intertidal zone of Dalian. Chin Sci Bull 58:2290-2297

Zhang Y, Bao HY, Nie YY, Lun YL, Dang ZW, Song C, Shao HY, Hu XQ (2016) Screening and tracing of anti-Alzheimer related bioactive constituents from marine fungi. Mod Food Sci Technol 32:63-71

Zhang FZ, Li XM, Li X, Yang SQ, Meng LH, Wang BG (2019) Polyketides from the mangrove-derived endophytic fungus Cladosporium cladosporioides. Mar Drugs 17:296

Zhao HQ, Zhou SD, Zhang MM, Feng JH, Wang SS, Wang DJ, Geng YL, Wang X (2016) An in vitro AChE inhibition assay combined with UF-HPLC-ESI-Q-TOF/MS approach for screening and characterizing of AChE inhibitors from roots of Coptis chinensis Franch. J Pharm Biomed Anal 120:235-240

Zhu T, Chen Z, Liu P, Wang Y, Xin Z, Zhu W (2014) New rubrolides from the marine-derived fungus Aspergillus terreus OUCMDZ-1925. J Antibiot (Tokyo) 67:315-318

\section{Affiliations}

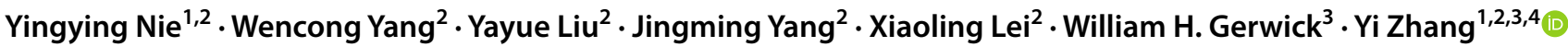

1 Center for Marine Drugs Research and Development, Shenzhen Institute of Guangdong Ocean University, Shenzhen 518000, China
2 College of Food Science and Technology, Key Laboratory of Guangdong Province Aquatic Products Processing and Safety, Guangdong Province Engineering Laboratory 
for Marine Biological Products, Guangdong Provincial Engineering Technology Research Center of Marine Food, Key Laboratory of Advanced Processing of Aquatic Products of Guangdong Higher Education Institution, Zhanjiang Municipal Key Laboratory of Marine Drugs and Nutrition for Brain Health, Research Institute for Marine Drugs and Nutrition, Guangdong Ocean University, Zhanjiang 524088, China
3 Center for Marine Biotechnology and Biomedicine, Scripps Institution of Oceanography, University of California, San Diego, La Jolla, CA 92093, USA

4 Collaborative Innovation Center of Seafood Deep Processing, Dalian Polytechnic University, Dalian 116034, China 